\title{
External Ventricular Drains and Mortality in Patients with Severe Traumatic Brain Injury
}

\author{
Donald E. G. Griesdale, Jonathan McEwen, Tobias Kurth, Dean R. Chittock
}

\begin{abstract}
Purpose: To determine our institutional adherence to the Brain Trauma Foundation guidelines with respect to intracranial pressure (ICP) monitoring, and examine the relationship between external ventricular drain (EVD) use and mortality. Materials \& Methods: Retrospective cohort study of 171 patients with severe traumatic brain injury (TBI). Propensity score adjusted logistic regression was used to model the association between EVD use and mortality. Results: EVDs were inserted in 98 of 171 patients. Of the 73 patients without an EVD, $63(86 \%)$ would have qualified for ICP monitoring under the current guidelines. EVDs were in situ for a median of 8 days (SD 6). In adjusted analyses, EVD use was associated with hospital mortality (OR 2.8, 95\% CI: $1.1-7.1, \mathrm{p}=0.04$ ) and 28-day mortality (OR $2.1,95 \%$ CI: $0.80-5.6, \mathrm{p}=0.13$ ). We observed significant modification of the association between EVD and 28-day mortality by GCS within 12 hours (p-interaction =0.04), indicating strong association only among those patients with GCS score of at least 6 (OR 5.0, 95\% CI: 1.5 - 16.7, p<0.01). Conclusions: The association of EVD with 28-day mortality was only apparent among patients with GCS score of $\geq 6$. Further research is warranted to further refine which patients may benefit from ICP monitoring.
\end{abstract}

RÉSUMÉ: Drain ventriculaire externe et mortalité chez les patients atteints de lésion cérébrale traumatique sévère. Objectif : Cette étude visait à déterminer la fidélité de notre institution aux lignes directrices de la Brain Trauma Foundation concernant la surveillance de la pression intracrânienne (PIC) et à examiner la relation entre l'utilisation d'un drain ventriculaire externe (DVE) et la mortalité. Matériels et méthodes : Il s'agit d'une étude rétrospective portant sur une cohorte de 171 patients atteints de lésion cérébrale traumatique (LCT). Nous avons utilisé une analyse de régression logistique ajustée pour l'indice de tendance pour modéliser l'association entre l'utilisation d'un DVE et la mortalité. Résultats : Un DVE a été mis en place chez 98 des 171 patients. Parmi les 73 patients qui n'ont pas reçu de DVE, 63 patients (86\%) auraient dû en recevoir un selon les lignes directrices actuelles. La médiane du temps pendant lequel le DVE a été laissé en place était de 8 jours (écart type de 6 jours). Les analyses ajustées ont montré que l'utilisation d'un DVE était associée à la mortalité hospitalière (RC 2,8; IC à $95 \%$ de 1,1 à 7,$1 ; \mathrm{p}=0,04)$ et à la mortalité au cours des 28 premiers jours (RC 2,1; IC à 95\% de 0,80 à 5,6; p = $0,13)$. Nous avons observé que l'association entre le DVE et la mortalité au cours des 28 premiers jours était modifiée significativement par le score à l'échelle de coma de Glasgow (SCG) dans les 12 premières heures (pinteraction $=0,04)$, ce qui indique une association importante seulement chez les patients dont le SCG était d'au moins 6 (RC 5,0; IC à 95\% de 1,5 à 16,7; p < 0,01). Conclusions : L'association entre le DVE et la mortalité au cours des 28 premiers jours n'était évidente que chez les patients dont le SCG était de 6 ou plus. Il faudra effectuer d'autres recherches pour mieux définir quels patients sont susceptibles de bénéficier de la surveillance de la PIC.

Can. J. Neurol. Sci. 2010; 37: 43-48

In the United States, 1.4 million traumatic brain injuries (TBI) occur every year resulting in 235,000 hospitalizations and 50,000 deaths. ${ }^{1}$ There are currently 5.3 million Americans living with TBI-related disability. ${ }^{1}$ Fortunately, intensive care unit (ICU) management of TBIs has improved. Implementation of national guidelines have resulted in increased survival, 2,3 decreased costs and length of stay, ${ }^{3}$ and improved favorable outcomes following TBI. ${ }^{4,5}$

Increased intracranial pressure (ICP) above $20 \mathrm{mmHg}$ is a strong predictor of poor outcome following TBI.$^{6-8}$ As such, ICP monitors have become integral in the ICU management of these
From the Department of Anesthesiology (DEGG, JM), Pharmacology \& Therapeutics; Department of Anesthesia (DEGG, JM), Department of Medicine, Division of Critical Care Medicine (DEGG, DRC), University of British Columbia \& Program of Critical Care Medicine, Vancouver General Hospital, Vancouver BC; Inserm Unit 708 Neuroepidemiology (TK), University Pierre et Marie Currie, Paris, France; Department of Epidemiology, Harvard School of Public Health \& Division of Preventive Medicine (TK), Department of Medicine, Brigham and Women's Hospital, Harvard Medical School, Boston, Massachusetts, USA.

Received June 22, 2009. Final Revisions Submitted August 27, 2009. Correspondence to: Donald E.G. Griesdale, Critical Care Medicine, Vancouver General Hospital, Room 2438, Jim Pattison Pavilion, 2nd Floor, 855 West 12th Avenue, Vancouver British Columbia, V5Z 1M9, Canada. 
patients and are currently a level II recommendation (moderate degree of clinical certainty) from the Brain Trauma Foundation (BTF). ${ }^{9}$ Despite these recommendations, there remains significant variability in practice of ICP monitoring. A survey of Canadian Neurosurgeons showed that although the majority use ICP monitoring in their patients, only $20.4 \%$ have a high level of confidence that routine monitoring improves outcomes in severe TBI. Nearly $80 \%$ felt that a prospective trial evaluating ICP monitoring is warranted. $^{10}$ Furthermore, a recent study demonstrated that although ICP monitoring was underutilized as per the BTF guidelines, it was associated with worsening of survival compared to the group who did not receive ICP monitoring. ${ }^{11}$ The literature is further complicated by various types of ICP monitors used clinically. With the unreliability of subarachnoid and extradural locations, intra-parenchymal monitors and external ventricular drains (EVDs) are currently the most widely used. EVDs have the added benefit of draining cerebrospinal fluid, thus functioning as both monitor and therapy for elevated ICP.

Thus, the goals of this study are twofold: (1) to examine the adherence to BTF guidelines within our institution, a Canadian tertiary academic ICU and (2) examine the relationship between EVD use on 28-day and hospital mortality.

\section{METHODS}

\section{Patient Inclusion \& Data Collection}

A retrospective cohort was constructed using the ICU database of all patients admitted to the ICU at Vancouver General Hospital with a severe TBI (Glasgow Coma Scale $(\mathrm{GCS})<=8$ ) between May 2000 and March 2006. Vancouver General Hospital is a 550 bed, tertiary care hospital affiliated with the University of British Columbia. The ICU is a closed, 27bed, mixed medical-surgical unit, which operates with a 1:1 nurse to patient ratio, with resident and fellow staff in attendance. We excluded patients who were obeying commands within 12 hours, indicating a non-severe TBI. We further excluded those who died within 12 hours of ICU admission, as these patients were likely to succumb irrespective of EVD status. None of these patients died from complications related to EVD insertion. Patients were also excluded if they had a concomitant high cervical spine injury or obvious non-traumatic causes of their decreased level of consciousness (e.g. aneurysmal subarachnoid hemorrhage) identified during the chart review. All charts were reviewed and data collected using standardized forms. Data acquired included information on the type of injury, ICU management and monitoring information. Type and severity of injury was characterized by: best GCS in 12 hours, mechanism and type of TBI (diffuse axonal injury, parenchymal contusions, extra-axial collections, basal skull or calvarial fractures), surgical procedures performed and features suggestive increased ICP on CT scan on from radiology reports (mixed density lesion $>25 \mathrm{~mm}$, midline shift $>5 \mathrm{~mm}$, cisternal compression) and baseline vital signs. Traumatic brain injury management included use of bolus mannitol in ER (dose $1 \mathrm{~g} / \mathrm{kg}$ ), cooling (target temperature and duration of therapy) and use of neuromuscular blockers. Monitoring data acquired included use of EVD, ICP measurements (if EVD present), use and values of jugular venous oximetry, and daily GCS. Demographic and outcome information, including 28-day and hospital mortality, were obtained from the ICU database. In addition, the ICU database contained the Acute Physiology and Chronic Health Evaluation (APACHE) II score, baseline admission laboratory values and vital signs for the first 24 hours.

\section{Traumatic Brain Injury Management}

Care of patients suffering TBI at our institution has been protocolized since 1995. All patients are maintained with: head of bed elevated above 30 degrees with their neck in a neutral position, mean arterial pressure $>=70 \mathrm{mmHg}$ (ensure adequate intravascular volume replacement with normal saline, and using norepinephrine infusion if required) and $\mathrm{PaO}_{2}>=70 \mathrm{mmHg}$. If ICP increases $>20 \mathrm{mmHg}$ for greater than five minutes without stimulation, the EVD is opened to $26 \mathrm{~cm} \mathrm{H}_{2} \mathrm{O}$ and cerebrospinal fluid is drained. Opened EVDs are closed every hour to measure ICP. Cerebral oxygen extraction ratio is maintained $<40 \%$ by ensuring adequate cerebral perfusion pressure, sedation and paralysis (if required), and careful titration of arterial $\mathrm{CO}_{2}$ tension to modify cerebral blood flow. In addition, hyperthermia is avoided by using acetaminophen $650 \mathrm{mg}$ every four hours and cooling blankets if required to keep the core temperature $<38$ degrees. More aggressive cooling measures may be instituted on an individual basis to maintain ICP $<20 \mathrm{mmHg}$ if the above maneuvers are insufficient.

\section{Statistical Analysis}

All analyses were performed with Stata 10.0 (StataCorp. 2007. Stata Statistical Software: Release 10. College Station, TX: StataCorp LP). Univariate analyses utilizing Fisher's exact testing for categorical data and independent t-tests for continuous data were used where appropriate. Wilcoxon ranksum tests were used for ordinal data, and non-normally distributed continuous data. All tests were two-sided and a pvalue $<0.05$ was considered statistically significant.

\section{Propensity Score \& Logistic Regression Model}

We used a multivariable logistic regression model to estimate the propensity of having an EVD inserted based on a large number of relevant covariates. Linearity in the log odds of continuous covariates was assessed visually, and by using likelihood ratio testing when constructing the propensity score. Covariates in the propensity score were selected based on their predictive ability to estimate insertion of an EVD $(p<0.2)$ and included: age, APACHE II score, increased ICP on computerized tomography scanning, administration of mannitol in the emergency room, year of admission, subdural hematoma, diffuse axonal injury, craniotomy performed, systolic blood pressure < $90 \mathrm{mmHg}$ and arterial oxygen tension $<70 \mathrm{mmHg}$. Including these variables in the propensity score eliminates associations of all of the included variables with EVD insertion, and thus confounding by these covariates. The final c-statistic of the propensity score was 0.79 .

We evaluated the association between EVD and 28-day and in-hospital mortality by using logistic regression models. These models included presence of EVD, GCS and the propensity score. We also assessed for effect measure modification of EVD on mortality by level of GCS by introducing an interaction term 
into the model. We used the Likelihood ratio test to assess the significance of the interaction in the final model.

The protocol was approved by Clinical Research Ethics Board at the University of British Columbia and Vancouver General Hospital.

\section{RESUlts}

Reviewed and included in the analysis were 273 charts and 171 patients. (Figure 1). The baseline characteristics are presented in Table 1. External ventricular drains were inserted in 98 patients. Patients in whom EVDs were inserted were younger, had lower best GCS within 12 hours, receive mannitol more frequently, were more likely to have a subdural hematoma or features suggestive of increased ICP on initial CT scan of the head, and undergo a craniotomy. Based on the current BTF guidelines for use of ICP monitors (GCS $<=8$ with an abnormality on CT scan), 63 of 73 patients in the non-EVD group would have qualified for ICP monitoring.

Outcomes by EVD status are presented in Table 2. Hypothermia and jugular mixed venous oximetry were used more frequently in patients with EVDs. Patients with EVDs spent more time being mechanically ventilated and had a longer stay in the ICU. Patients with EVDs tended to have higher 28day mortality $(23 \%$ vs. $12 \%, \mathrm{p}=0.07)$ and hospital mortality ( $29 \%$ vs. $12 \%, \mathrm{p}<0.01)$. The EVDs remained in situ for a median of eight days (SD six days).

In adjusted analyses, EVD use was associated with hospital mortality (OR 2.76, 95\% CI: 1.07, 7.08, p=0.04) and 28-day mortality (OR 2.12, 95\% CI: $0.80,5.62, \mathrm{p}=0.13$ ), although the latter did not reach significance. Subgroup analysis demonstrated significant effect measure modification of EVD on mortality by level of GCS (Figure 2) in a propensity score-adjusted model (p

Table 1: Baseline patient characteristics by EVD status

\begin{tabular}{|c|c|c|}
\hline & $\begin{array}{c}\begin{array}{c}\text { EVD Inserted } \\
(n=98)\end{array} \\
\end{array}$ & $\begin{array}{c}\text { No EVD } \\
(n=73)\end{array}$ \\
\hline Age, y $\left(S D^{a}\right)$ & $35(15.4)$ & $42(18.0)^{* *}$ \\
\hline Female gender, $n(\%)$ & $21(21.4)$ & $18(24.7)$ \\
\hline Mean APACHE ${ }^{b}$ II $\left(S^{a}{ }^{a}\right)$ & $23.5(4.5)$ & $23.4(5.0)$ \\
\hline $\mathrm{SBP}^{c}<90 \mathrm{mmHg}, \mathrm{n}(\%)$ & $20(20.4)$ & $12(16.4)$ \\
\hline $\mathrm{PaO}^{d}<70 \mathrm{mmHg}, \mathrm{n}(\%)$ & $10(10.2)$ & $5(6.8)$ \\
\hline \multicolumn{3}{|l|}{ Best $\mathrm{GCS}^{\mathrm{e}}$ in 12 hours $\left(\mathrm{SD}^{\mathrm{a}}\right)$} \\
\hline GCS $<6, n(\%)$ & $42(42.9)$ & $10(13.7)^{\star \star}$ \\
\hline GCS $6-8, n(\%)$ & $51(52.0)$ & $53(72.6)^{\star \star}$ \\
\hline GCS $9-12, n(\%)$ & $5(5.1)$ & $10(13.7)^{\star \star}$ \\
\hline Mannitol, $\mathrm{n}(\%)$ & $61(62.2)$ & $24(32.9)^{\star *}$ \\
\hline \multicolumn{3}{|l|}{ CT Head, n(\%) } \\
\hline Traumatic SAH $^{f}$ & $49(50.0)$ & $42(57.5)$ \\
\hline $\mathrm{DAl}^{g}$ & $33(33.7)$ & $19(26.0)$ \\
\hline Subdural hematoma & $46(46.9)$ & $20(27.4)^{\star \star}$ \\
\hline Features of Increased ICP ${ }^{h}$ & $62(63.3)$ & $25(34.2)^{* *}$ \\
\hline Basal Skull Fracture & $23(23.5)$ & $19(26.0)$ \\
\hline Craniotomy performed, n(\%) & $44(44.9)$ & $21(28.8)^{*}$ \\
\hline
\end{tabular}

${ }^{\mathrm{a}}$ standard deviation; ${ }^{\mathrm{b}}$ Acute Physiology and Chronic Health Evaluation; ${ }^{\mathrm{c}}$ systolic blood pressure in $\mathrm{mmHg}$; ${ }^{\mathrm{d}}$ arterial partial pressure of oxygen in $\mathrm{mmHg}$; ${ }^{\mathrm{e}}$ Glasgow Coma Scale; ${ }^{\mathrm{f}}$ subarachnoid hemorrhage; ${ }^{\mathrm{g}}$ diffuse

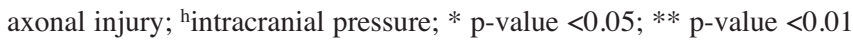

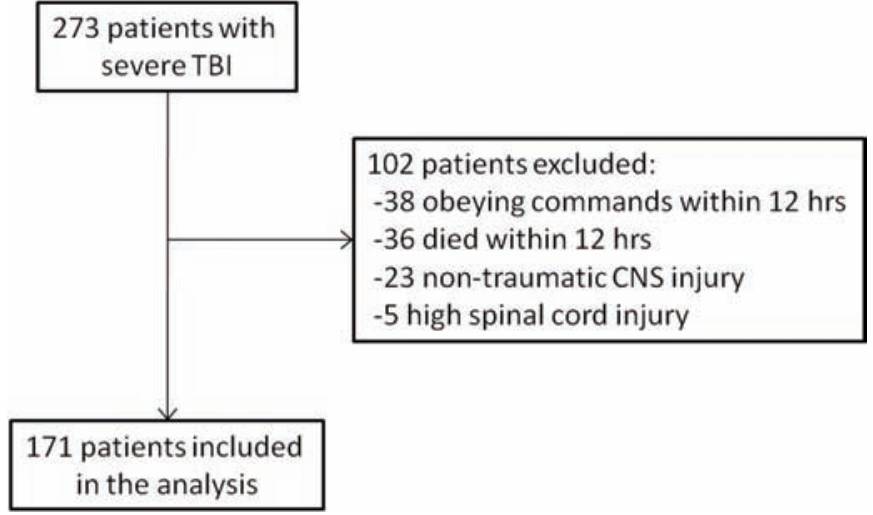

Figure 1: Cohort selection and reason for exclusion.

interaction $=0.04$ ). In other words, the risk of EVD on mortality differed by levels of GCS in the first 12 hours. In patients without an EVD, the probability of 28-day mortality decreased with increasing GCS. However, in patients with an EVD, the probability of 28-day mortality did not appear to change much with increasing GCS. As part of an exploratory analysis to quantify the differential effect of EVD on mortality, GCS was dichotomized to less than 6 versus 6 or greater based on the intersection of the probability distribution curves in Figure 2. The adjusted results are presented in Table 3. Test of interaction was repeated using the dichotomized GCS score and remained significant ( $\mathrm{p}=0.01$ for 28 -day mortality and $\mathrm{p}=0.03$ for hospital mortality). When GCS was less than 6, use of EVDs were not

Table 2: ICU management and outcomes by EVD status

\begin{tabular}{|c|c|c|c|}
\hline & $\begin{array}{c}\begin{array}{c}\text { EVD Inserted } \\
(n=98)\end{array} \\
\end{array}$ & $\begin{array}{c}\text { No EVD } \\
(n=73)\end{array}$ & p-value \\
\hline $\begin{array}{l}\text { Therapeutic } \\
\text { hypothermia } \\
<35^{\circ} \mathrm{C}, \mathrm{n}(\%)\end{array}$ & $32(32.7)$ & 0 & $<0.001$ \\
\hline $\begin{array}{l}\text { Therapeutic } \\
\text { hypothermia } \\
<38^{\circ} \mathrm{C}, \mathrm{n}(\%)\end{array}$ & $52(53.1)$ & $6(8.2)$ & $<0.001$ \\
\hline $\begin{array}{l}\text { Jugular bulb } \\
\text { inserted, } n(\%)\end{array}$ & 78 (79.6) & $2(2.7)$ & $<0.001$ \\
\hline $\begin{array}{l}\text { Median days } \\
\text { of } E V D^{a}\left(S^{b}\right)\end{array}$ & $8(8.2)$ & 0 & $<0.001$ \\
\hline $\begin{array}{l}\text { Median days } \\
\text { of } \mathbf{M V}^{c}\left(S D^{b}\right)\end{array}$ & $12.2(11)$ & $5.2(7)$ & $<0.001$ \\
\hline $\begin{array}{l}\text { Median ICU } \\
\text { days }\left(S^{b}{ }^{b}\right)\end{array}$ & $14(11)$ & $6(8)$ & $<0.001$ \\
\hline $\begin{array}{l}\text { 28-day } \\
\text { Mortality, n(\%) }\end{array}$ & $22(22.4)$ & $9(12.3)$ & 0.07 \\
\hline $\begin{array}{l}\text { Hospital } \\
\text { Mortality, n(\%) }\end{array}$ & $28(28.6)$ & $9(12.3)$ & $<0.01$ \\
\hline
\end{tabular}

aexternal ventricular drain; ${ }^{\mathrm{b}}$ standard deviation; ${ }^{\mathrm{c}}$ mechanical ventilation 


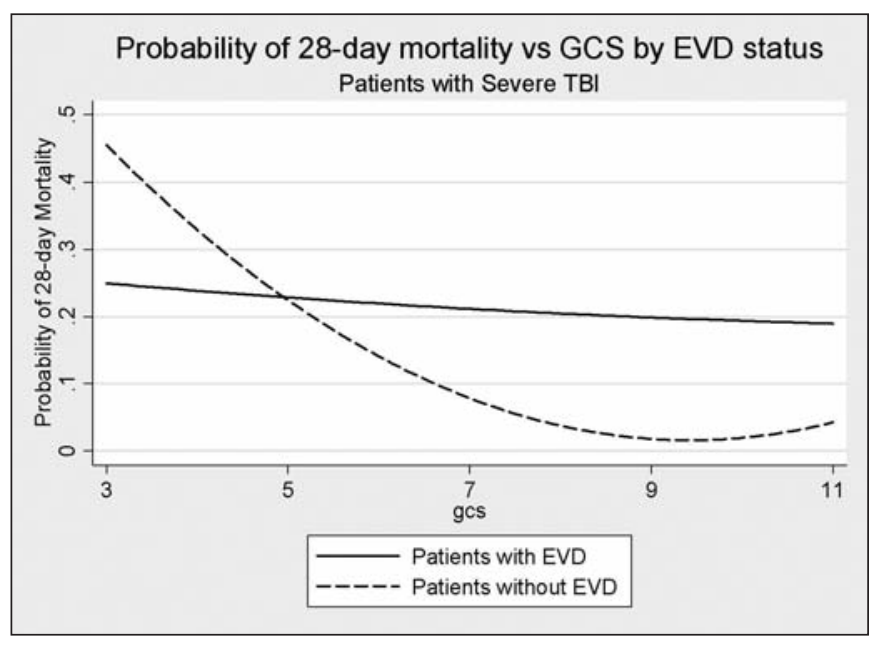

Figure 2: Probability of 28-day mortality versus admission GCS by EVD status. Solid line represents patients with an EVD while the dashed line represents patients without an EVD. Subgroup test of interaction p-value is 0.04 indicating that there that the probability of mortality between those with and EVD and those without, differs by their admission GCS.

associated with 28-day mortality (OR $0.47,95 \%$ CI: $0.11-2.1$, $\mathrm{p}=0.32$ ) or hospital mortality (OR $0.76,95 \%$ CI: $0.18-3.2$, $\mathrm{p}=0.71$ ). However, when GCS was 6 or greater, EVDs were associated with an increased risk of 28-day mortality (OR 5.0, 95\% CI: $1.5-16.7, \mathrm{p}<0.01)$ and hospital mortality (OR 5.6, 95\% CI: $1.7-18.4, \mathrm{p}<0.01)$.

\section{DISCUSSION}

In our study, EVD use was associated with a longer ICU length of stay and days of mechanical ventilation in patients with severe traumatic brain injuries admitted to the ICU. Propensity score-adjusted, multivariable regression modeling demonstrated that EVD use was associated with increased risk of hospital mortality $(\mathrm{p}=0.04)$ and 28-day mortality $(\mathrm{p}=0.13)$. However, this association was entirely driven by a substantially increased risk among patients with a GCS score of at least 6 .

A recent retrospective study showed decreased survival associated with ICP monitoring; however, only $46 \%$ of the ICP monitors in their cohort were ventriculostomies. ${ }^{11}$ As such, one of the main benefits of EVDs, drainage of CSF to treat intracranial hypertension, was not present in the majority of their cohort. Furthermore, the authors did not examine for effect modification of ICP monitoring by admission GCS. It's not surprising that the association of EVDs on mortality may depend on GCS. As patients with higher GCSs will tend to have less severe TBIs, the potential benefit to ICP monitoring may decrease. As expected, patients in our study with EVDs had more interventions aimed at reducing ICP, including sedation and neuromuscular blockade, which themselves increase morbidity in critically ill patients. ${ }^{12,13}$ Our results are in keeping with a recent observational study by Cremer and colleagues which demonstrated that compared to patients without ICP monitoring, those with ICP / CPP targeted therapy had longer duration of mechanical ventilation, and increased intensity of therapy as defined by increased use of sedatives, mannitol, vasopressors and barbiturates. ${ }^{14}$ Thus, patients with less severe brain injuries would expect to benefit less from ICP monitoring, yet still be subjected to the therapies used to reduce ICP.

Another consideration is the duration of ICP monitoring. As patients improve and their ICPs normalize, the potential benefit of an EVD would diminish. The median length of EVD use in our cohort was eight days, with $44 \%$ of EVDs being in situ for ten or more days. A recent study of patients with severe TBIs by Stocchetti demonstrated a peak ICP in $80 \%$ of cases by Day 5 , and $99 \%$ by Day $10 .{ }^{15}$ Thus, very few patients would benefit from ICP monitoring for greater than ten days. After Day 6, the mean ICPs in our cohort were less than $16 \mathrm{mmHg}$, regardless if the EVD was removed that day or not. As such, the use of EVDs in less severely ill patients, or for a protracted period of time, may suffer the same limitations as the pulmonary artery catheter, which themselves have failed to improve outcomes in all but the most severely ill patients. ${ }^{16-18}$

Table 3: Propensity score-adjusted multivariable model of EVD status on mortality by level of GCS

\begin{tabular}{ccccc}
\hline Outcome & $\mathbf{O R}^{\mathbf{a}}$ & $\mathbf{s e}^{\mathbf{b}}$ & $\mathbf{9 5 \%} \mathbf{C l}^{\mathbf{c}}$ & $\mathbf{p}$-value \\
\hline 28-day Mortality $\dagger$ & & & & \\
Overall & & & & \\
GCS <6 & 2.1 & 1.1 & $0.80,5.6$ & 0.13 \\
GCS $>=6$ & 0.47 & 0.36 & $0.11,2.1$ & 0.32 \\
Overall & 5.0 & 3.1 & $1.5,16.7$ & $<0.01$ \\
GCS < 6 & & & & \\
GCS $>=6$ & 2.8 & 1.3 & $1.1,7.1$ & 0.04 \\
Hospital Mortality & 0.76 & 0.56 & $0.18,3.2$ & 0.71 \\
& 5.6 & 3.4 & $1.7,18.4$ & $<0.01$ \\
\hline
\end{tabular}

${ }^{\mathrm{a}} \mathrm{OR}=$ odds ratio adjusted for age, APACHE, increased ICP on CT, mannitol, year of admission, craniotomy, subdural hematoma, diffuse axonal injury, systolic blood pressure $<90$ $\mathrm{mmHg}$ and arterial oxygen tension $<70 \mathrm{mmHg}$; ${ }^{\mathrm{b}}$ standard error; ${ }^{\mathrm{c}} 95 \%$ confidence intervals; $\dagger$ $\mathrm{p}=0.01, \ddagger \mathrm{p}=0.03$ for interaction 
Much like the pulmonary artery catheter, use of EVDs is subject to strong confounding by indication. In spite of wellrecognized guidelines, physicians will utilize ICP monitoring based on clinical judgment. As such, determining an unbiased estimate of the association of EVD with mortality is difficult, even if information on important confounders is available. We have made efforts to reduce confounding by restricting our cohort to have more comparable EVD and non-EVD groups. However, confounding by indication may still be present in our data, as patients receiving EVDs were younger, with a lower GCS, and more likely to have features of increased ICP on admission CT scan. This type of confounding was also observed in a recent cohort study from Austria, where ICP monitors were more likely to be inserted in younger patients, females and those with isolated TBIs. ${ }^{19}$ In their study, patients with higher severity of illness, as measured by the Abbreviated Injury Scale of the head, were more likely to receive ICP monitoring. Increased intracranial pressure monitors were not associated with mortality, although they did not present outcomes by level of GCS, nor examine for interaction effects of ICP monitors by level of the Abbreviated Injury Scale or GCS. As with all observational data, unmeasured or residual confounding remains an alternative explanation for our findings. Additionally, in only considering mortality, we are not able to determine potential functional outcomes associated with EVD use in our population. Finally, generalizability is limited to ICUs with similar patient profiles and practice patterns as our own.

Strengths of our study include detailed clinical information from the chart using standardized data collection forms, uniform ICP monitor type, and use of propensity score-adjusted logistic regression modeling for control of confounding. Using this approach, we were able to control for a wide range of potential confounders. Propensity score adjusted models are less biased, more robust, and have greater power than traditional logistic regression when there are few outcome events. ${ }^{20,21}$

Within the strict guidelines of the BTF, EVDs were underutilized in our cohort. However, this may simply reflect the baseline differences between groups as mentioned previously. As such, it may be that clinicians are appropriately triaging the use of EVDs to those patients who are more severely ill. Although EVDs were associated with an increased 28-day and hospital mortality, this was only apparent in the subgroup of patients who had a better neurologic status in the first 12 hours (GCS >=6). Thus, further study to identify patients who may benefit from EVD use is warranted. In the meantime, given the association between intracranial hypertension and poor outcomes, ${ }^{6,7,22}$ coupled with evidence demonstrating a high risk of intracranial hypertension with GCS $\leq 8$ and an abnormal CT head, ${ }^{8}$ it is difficult to recommend more restricted use of EVDs. However, clinicians should consider removing EVDs soon after the ICP begins to abate, and the patient can be followed clinically.

In conclusion, we have demonstrated that EVD use was associated with increased mortality; however, this was driven entirely by those patients with a best GCS $\geq 6$. Further research is warranted to further refine which patients may benefit from ICP monitoring.

\section{Disclosures}

Dr. Kurth has received within the last two years investigatorinitiated research funding from the National Institutes of Health and Merck. Further, he is a consultant to i3 Drug Safety and World Health Information Science Consultants, LLC; he received honoraria from Genzyme, Merck, and Pfizer for educational lectures.

\section{REFERENCES}

1. Langlois JA, Rutland-Brown W, Wald MM. The epidemiology and impact of traumatic brain injury: a brief overview. J Head Trauma Rehabil. 2006;21(5):375-8.

2. Rusnak M, Janciak I, Majdan M, Wilbacher I, Mauritz W, Australian Severe TBI Study Investigators. Severe traumatic brain injury in austria VI: effects of guideline-based management. Wien Klin Wochenschr. 2007;119(1-2):64-71.

3. Fakhry SM, Trask AL, Waller MA, Watts DD, IRTC Neurotrauma Task Force. Management of brain-injured patients by an evidence-based medicine protocol improves outcomes and decreases hospital charges. J Trauma. 2004;56(3):492-9.

4. Patel HC, Menon DK, Tebbs S, Hawker R, Hutchinson PJ, Kirkpatrick PJ. Specialist neurocritical care and outcome from head injury. Intensive Care Med. 2002;28(5):547-53.

5. Palmer S, Bader MK, Qureshi A, Palmer J, Shaver T, Borzatta M, et al. The impact on outcomes in a community hospital setting of using the AANS traumatic brain injury guidelines. Americans Associations for Neurologic Surgeons. J Trauma. 2001;50(4): 657-64.

6. Saul TG, Ducker TB. Effect of intracranial pressure monitoring and aggressive treatment on mortality in severe head injury. J Neurosurg. 1982;56(4):498-503.

7. Juul N, Morris GF, Marshall SB, Marshall LF. Intracranial hypertension and cerebral perfusion pressure: influence on neurological deterioration and outcome in severe head injury. $\mathrm{J}$ Neurosurg. 2000;92:1-6.

8. Narayan RK, Kishore PR, Becker DP, Ward JD, Enas GG, Greenberg RP, et al. Intracranial pressure: to monitor or not to monitor? A review of our experience with severe head injury. J Neurosurg. 1982;56(5):650-9.

9. Brain Trauma Foundation, American Association of Neurological Surgeons, Congress of Neurological Surgeons, Joint Section on Neurotrauma and Critical Care, AANS/CNS. Guidelines for the management of severe traumatic brain injury. VI. indications for intracranial pressure monitoring. J Neurotrauma. 2007;24 Suppl $1: \mathrm{S} 37-44$

10. Sahjpaul R, Girotti M. Intracranial pressure monitoring in severe traumatic brain injury--results of a Canadian survey. Can J Neurol Sci. 2000;27(2):143-7.

11. Shafi S, Diaz-Arrastia R, Madden C, Gentilello L. Intracranial pressure monitoring in brain-injured patients is associated with worsening of survival. J Trauma. 2008;64(2):335-40.

12. Cook DJ, Walter SD, Cook RJ, Griffith LE, Guyatt GH, Leasa D, et al. Incidence of and risk factors for ventilator-associated pneumonia in critically ill patients. Ann Intern Med. 1998;129(6):433-40.

13. Girard TD, Kress JP, Fuchs BD, Thomason JW, Schweickert WD, Pun BT, et al. Efficacy and safety of a paired sedation and ventilator weaning protocol for mechanically ventilated patients in intensive care (awakening and breathing controlled trial): a randomised controlled trial. Lancet. 2008;371(9607):126-34.

14. Cremer OL, van Dijk GW, van Wensen E, Brekelmans GJ, Moons $\mathrm{KG}$, Leenen LP, et al. Effect of intracranial pressure monitoring and targeted intensive care on functional outcome after severe head injury. Crit Care Med. 2005;33(10):2207-13.

15. Stocchetti N, Colombo A, Ortolano F, Videtta W, Marchesi R, Longhi $\mathrm{L}$, et al. Time course of intracranial hypertension after traumatic brain injury. J Neurotrauma. 2007;24(8):1339-46.

16. Chittock DR, Dhingra VK, Ronco JJ, Russell JA, Forrest DM, Tweeddale M, et al. Severity of illness and risk of death associated with pulmonary artery catheter use. Crit Care Med. 2004;32(4):911-5. 
17. National Heart, Lung, and Blood Institute Acute Respiratory Distress Syndrome (ARDS) Clinical Trials Network, Wheeler AP, Bernard GR, Thompson BT, Schoenfeld D, Wiedemann HP, et al. Pulmonary-artery versus central venous catheter to guide treatment of acute lung injury. N Engl J Med. 2006;354(21): 2213-24.

18. Chittock DR. The pulmonary artery catheter and critical care: the cart is before the horse. Crit Care Med. 2006;34(6):1820-2.

19. Mauritz W, Steltzer H, Bauer P, Dolanski-Aghamanoukjan L, Metnitz P. Monitoring of intracranial pressure in patients with severe traumatic brain injury: an Austrian prospective multicenter study. Intensive Care Med. 2008;34(7):1208-15.
20. Peduzzi P, Concato J, Kemper E, Holford TR, Feinstein AR. A simulation study of the number of events per variable in logistic regression analysis. J Clin Epidemiol. 1996;49(12):1373-9.

21. Cepeda MS, Boston R, Farrar JT, Strom BL. Comparison of logistic regression versus propensity score when the number of events is low and there are multiple confounders. Am J Epidemiol. 2003;158(3):280-7.

22. Miller JD, Butterworth JF, Gudeman SK, Faulkner JE, Choi SC, Selhorst JB, et al. Further experience in the management of severe head injury. J Neurosurg. 1981;54(3):289-99. 